\title{
Rational Forms And Methods Of Learning In Creative Universities Of Uzbekistan
}

\author{
${ }^{1}$ Antonina Kosheleva, ${ }^{2}$ Shakhnoza Sabirova, ${ }^{3}$ Timur Sabirov \\ ${ }^{1}$ Candidate of Pedagogical Sciences, Associate Professor of the Department of Pedagogy and Psychology, Uzbekistan State \\ Institute of Arts and Culture, Tashkent, Uzbekistan. \\ ${ }^{2}$ Phd student, Uzbekistan State Institute of Arts and Culture, Tashkent, Uzbekistan. \\ ${ }^{3}$ Master's student, Tashkent State Pedagogical University, Tashkent, Uzbekistan.
}

\begin{abstract}
The purpose of the article is to outline the most effective forms and methods of teaching in universities of a creative nature in the Republic of Uzbekistan. The authors of the article pay serious attention to the current forms of education in an innovative manner. The article presents educational forms of training in creative universities, which are used in Uzbekistan and have proven their effectiveness in training.

A special place is given to the forms and means of teaching, the orientation of teaching to a creative audience, the use of innovative methods that have proven their rationality in the process of educating creative workers that meet modern requirements for specialists in creative professions in modern conditions.

The authors focused their attention on the problems of forming a harmoniously developed personality in the educational process of creative universities. The results of the research consist in the scientific and theoretical study and identification from the pedagogical point of view of the problems of forming a harmonious personality in the educational space. New approaches have been studied and applied in the education of Uzbekistan; favorable conditions for the effective development of the creative potential of students are highlighted.

When considering the peculiarities of the educational process in creative universities, a special place was given to the creation of mechanisms for flexible thinking in students, in which the ability to vary the methods of solving various creative problems arises, to choose the most optimal ways to solve them, to find the most original forms of embodiment.
\end{abstract}

Keywords:

innovation, creative audience, forms of education, rational method, educational process, high school.

Article Received: 18 October 2020, Revised: 3 November 2020, Accepted: 24 December 2020

\section{Introduction}

In modern conditions of dynamic development of Uzbekistan, a special place is given to the educational process, which was expressed in the preparation of the most important fundamental documents for higher education: on September 23, 2020, the President of the Republic of Uzbekistan Shavkat Mirziyoyev approved the Law of the Republic of Uzbekistan "About Education".

To ensure the dynamism of the development of higher education pedagogy in all its manifestations in education, there is an urgent need for research and methodological work to identify the most effective and rational forms and methods of building the educational process in the course of training specialists of a new formation in all areas.

In the field of the framework of our article, we pay serious attention to the existing forms of education in creative universities of Uzbekistan in an innovative manner, which have shown them quite effectively. Great attention has always been paid to serious problems of educational forms in the educational process, and this is not accidental. Educational forms of education in creative universities are very numerous and unique.

The word "forma" is of Latin origin, meaning the external outline, appearance, structure of something. As a rule, in relation to training, this concept - "form" is used in two meanings: the form of training and the form of organization of training, the interpretation of these terms is different, has different explanations and still causes controversy among scientists.

A typical form of teaching as a didactic category means the external side of the organization of the educational process, and it 
depends on the goals, content, methods and means of teaching, material conditions, the composition of the participants in the educational process, the structure of its organization, and methods of presentation.

The form of organization of training is presented by us as a way of providing educational services, which takes into account not only the mode of life of the students, but also its sociopsychological characteristics and other characteristics.

Among the forms of organization of education in Uzbekistan, the cognitive activity of teachers and students is clearly presented. It is this form that is characterized by systematicity and consistency, integrity and clear definition of the leading didactic goals, among which taking into account the specifics of the university is of no small importance.

The successful implementation of the forms of training depends on the composition of the students, the duration of training, and the location. As you know, among the main forms of higher education, the most frequently used are lectures and seminars; in a creative university - master classes, binary lectures (interdisciplinary "lecture together"), trainings (audio, video), debriefing, debates, forum (one of the forms of educational discussion) and lecture - conference. These are the most successfully used forms of education in creative universities.

This classification of basic forms of organization of training should be based on possible structures of human interaction. In this case, the following possible situations should be taken into account: indirect communication, communication in a couple and communication in a group. In turn, in a group there can be two different structures of interaction of its participants: "one speaks, does - the rest listen, observe" (one communicates with several as one) and "each communicates with each in turn." Those who are nearby, but doing autonomous individual work, do not represent the group. There are collective, group, individual, frontal (oral survey), classroom and out-of-class, forms of education. Such classifications are not strictly scientific, but they allow to somewhat streamline the variety of forms of education in a higher educational institution.

The most common in the educational process is the collective form, which is considered as functioning in an integral team, with all the features of interaction when submitting and consolidating educational material: the technology of using game methods in teaching: role-playing, business and other types of educational games.

In group forms of education, students work in groups created on various bases (in our case, we are often talking about small groups - 5-6 people), which are most successfully used in technologies such as brainstorming and brainstorming: problem learning, learning technology inventive problems (TRIZ), and learning in cooperation (team, group work, and information and communication technologies;

It is well known that an individual form of education implies the interaction of a teacher with one student, while student-centered learning is effectively carried out.

As for the frontal form of teaching, it involves the teacher's work with all students at once at the same pace and with common tasks. This form can be used with all of the above learning technologies, but is especially effective in the educational process in creative universities.

There are classroom and out-of-class forms of training, they are associated with the place of the classes and their use is dictated by the available training tools and the set goals and objectives.

The concepts "form of organization of training" or "organizational form of training" is different. As a rule, they are considered synonymous, but these concepts are not identical:

The form of organization of training is the construction of a separate link in the learning process, a certain type of activity (lesson, lecture, seminar, excursion, optional lesson, exam, etc.).

Organizational forms of training are certain types of training sessions that differ from each 
other in the goals set, the number and composition of the students, the place and time, and the content of teaching activities. In the organizational forms of training, the process of interaction of the training content with the management of educational activities is implemented.

The main goal of learning determines the structural interactions of all elements that form the basis of the educational process. Among the multiple forms of the educational system of higher education, we have chosen the following: forms of classes - introductory, on the submission of basic knowledge of the topic under study, on deepening the knowledge of the presented topic, on systematization and generalization of knowledge, on control of the knowledge gained. This system of forms of classes was created on the basis of research of methodologists and applied when creating textbooks by the authors of this article.

An important role in the choice of forms of employment in creative higher educational institutions of the Republic of Uzbekistan is played by those that can ensure the "inclusion" of various creative tasks in the educational process: master classes, role-playing games, trainings, contests, interviews with honored workers of art and culture. Forms of classes based on held festivals, forums, and creative meetings are especially effective.

Traditional forms of organization of training, such as: collective lessons, individual lessons, collective-group and individuallycollective. Individual lessons include tutoring, tutoring, mentoring, family learning, and selfstudy.

\section{Materials and methods}

Training of specialists for creative universities, the pedagogical process of training a modern specialist in the field of culture from the point of view of form and content are disclosed in the works of A.Yu. Butova, T.I. Baklanova, N.K. Baklanova, A.D. Zharkova, L.S. Zharkova, A.S. Kargipa, N.A. Parshikova, T.M., Smirnova, Yu.S. Streltsova, E.Yu. Streltsova, V.M. Chizhikova, N.N. Yaroshenko.
It should be noted that the diverse forms of the modern educational process in creative universities have not yet been fully investigated; their study is an urgent, urgent problem of didactics that requires its resolution. Scientists from many countries are now aiming at solving it: not only has the level of training of highly qualified specialists depended on this, but also the general state of affairs in world pedagogy.

Students of creative universities have an increasing need to determine the most promising professional strategy based on the real possibilities of transformative development, the value-semantic orientation of which is determined by the desire to realize the highest humanistic principles by means of art. And this is one of the most urgent tasks being solved by teachers and scientists of Uzbekistan at the moment.

It is known that value orientations satisfy the needs of a student's personality - a future specialist in the field of art and culture in line with the humanistic position during the transition to a new historical and cultural state of society.

"The need for society to use the developing potential of the humanitarian education system in order to unleash the creative potential of students should be carried out by an approach to determining the content, forms and methods of teaching and the objective needs of a qualitative transformation of the learning process, only in accordance with the already existing traditionally established values, the mentality of the country" noted the first President of Uzbekistan I.A. Karimov. "

The creative work of a modern teacher teaching in creative universities of Uzbekistan, in the presence of a living, genuine essence, is undoubtedly multifaceted, inspired, plastic and sensitive in the spiritual sense, completely freed from the rigid framework, planned levels and "iron" tools of influence on students. How the conditions of an unlimited creative atmosphere in the pedagogical process affect the monitoring of the personal growth of students and their self- 
improvement are of particular interest for our scientific search.

The newest educational system of subjectsubject relations in the educational process within the framework of the State Institute of Arts and Culture of Uzbekistan is designed to establish close ties between the teacher and the student, which open each person in a completely new way. The professional orientation of this university to interact with a single human individuality generates close psychological ties between two mutually influencing subjects, in which each of them learns, to a certain extent, a peculiar, unique world of thoughts, a set of a diverse range of human feelings, emotions and interests. It is in this that we see favorable preconditions for the training of specialists of a new formation that meet world requirements. The essence of such connections is creativity itself, which recreates each person, introduces unexplored elements of novelty, encouraging her to cultivate a system of such relationships under the influence of each creator.

\section{Result and discussion}

The problems solved by teachers of creative universities are complex and multifaceted. The most important among them are those that allow solving the problem of training specialists of a new formation, competent and versatile, creative and independent. Today, the activities of creative universities are filled with a special content: in their area, along with highly specialized subjects, there are a number of humanitarian disciplines designed to create favorable preconditions for training specialists with a broad outlook in the most important spheres of art and culture, possessing solid professional knowledge and broad creative potential.

Achievement of positive shifts in solving such complex problems can only be achieved by a teacher who is competent in all areas of knowledge, someone who is always in search, in an effort to comprehend new things and apply it in their professional activities.

In the modern educational process, the key is the understanding that personality development comes to the fore in teaching.

In this case, the most important property noted by the psychologist A. A. Leontiev is realized: "A person does not just master the range of linguistic knowledge. He masters or assimilates the system of ideas and views that they express." Indeed, cultural and historical values are comprehended in the process of studying the disciplines of the humanitarian cycle: languages, literature, history, pedagogy, psychology, while the most important values of different eras and peoples are compared and, as a result, a person is formed who can integrate, penetrate into the sphere of various cultural historical relations, create original works of high social value.

The scientific potential of prominent world and Uzbek teachers and scientists in the educational process is aimed at finding ways to optimize learning, many of which are inherently innovative. A special role in modern methodological, pedagogical and psychological literature is assigned to the problem of pedagogical communication, which is considered as the need for joint creative activity in the course of direct communication between the teacher and the students. The problems of pedagogical communication were studied by Yu.P. Azarov, Ya.V. Bondarevskaya, B.T. Likhacheva, V.F. Shatalov, I.P. Volkov, N. Azizkhodzhaeva, E.A. Seytkhalilov.

The most significant are: the importance of pedagogical communication in teaching and upbringing; the need for organic sociopsychological interaction between the teacher and the students, the content of which is the exchange of information, the organization of relationships, the provision of educational impact.

We consider the creation of such an environment as paramount in pedagogical communication with creative youth, in which pedagogical communication becomes a special type of creativity, which finds expression in the ability to convey educational information, taking into account the nature and characteristics of each 
student and the entire audience as a whole. In this synthesis, the authors see the key to solving complex problems of the modern educational process in creative universities of Uzbekistan.

Communication in world pedagogy is considered as a step-by-step process: a) modeling (preparatory stage); b) direct communication (communicative stage); c) communication management in the pedagogical process; d) analysis of communication and modeling of new pedagogical tasks.

In the course of pedagogical communication in a creative university, it is necessary to create conditions for the self-development of a creative individual and the disclosure of its potential, provide opportunities for personal and professional growth, the development of spiritual strength, abilities and talent. Without this, it is impossible to achieve optimal results of the educational process of a creative university.

It should be noted that the joint personal and professional growth of the teacher and students is the goal and the main component of a properly organized pedagogical communication in the modern pedagogical process, and this goal predetermines the inclusion of the necessary teaching aids that correspond to the didactic principles of higher education.

The following approaches should be put in the basis of rational, giving positive results of pedagogical communication in a creative university: deep humanism based on knowledge of the qualities and characteristics of students, democracy, allowing a pluralism of opinions and assessments, mutual respect of the teacher and students, reliance on the interests and needs of students, taking into account their real abilities (in some cases - talent). Involving trainees in a joint activity with a teacher to obtain the truth is not a new process, it has been known since the time of Socrates, but the forms and methods today are qualitatively different than in the era of antiquity.

If we talk about the super task of teaching in a modern creative university, then we would formulate it as "teaching creativity". And in this difficult process, there are no specific methods, since the manifestation of creativity is so diverse that it is very difficult, and sometimes impossible, to draw the line between high-level professionalism and creativity. In the process of true creativity, new valuable works, images are created, the potential of a creative personality is revealed.

Experience has shown that the most favorable in teaching creativity is the combination of traditional teaching methods and methods with innovative approaches. At the same time, educational activities should be aimed at developing the qualities necessary for the formation and development of a creative personality: inventiveness, resourcefulness, mental ingenuity, independence, originality.

\section{Conclusion}

So in the course of training, the formation of the personality of the future Creator, Artist, Man with a capital letter takes place in the course of educational training by means of art, through the images of fiction, understanding the history of his people. And this is what we call a tradition in upbringing and education, a tradition that we will never give up.

Skillful inclusion in the educational process of elements of innovation, innovations in the complex and favorable business of forming a creative personality, disclosing its potential has become the originality of the approach to solving educational and educational problems in new conditions.

It should be recognized the complexity of the specifics of modern pedagogical activity is to select the most valuable, truly beautiful that has developed in the process of socio-historical practice, and pass it on to the younger generation, enriching it with new approaches, modern ideas based on explanatory-illustrative and problemdeveloping education, giving preference to the latter, innovative in essence.

An important place in a number of teaching methods used in creative universities is occupied by training, as the most capacious and variable 
form of presentation and consolidation of educational material, which allows to evoke emotional reactions of students, to activate their thinking abilities. In the process of training education, training is actually carried out in cooperation, which provides for all levels of communication and reliance on them, the use of various active (traditional and new) methods of psychology and pedagogy, which lead students to self-knowledge, self-development, the formation and development of effective behavior in constantly changing living conditions, development of communication skills.

As a rule, a teacher acts as a leader in the training, but it can be an expert, a leader, or a director. Training exercises are a tool in the hands of the master; it is the personality of the trainer that determines the success of the impact on the trainees - the training participants. The interest of the trainees in the educational process directly depends on how skillfully the training is conducted.

It is within the framework of the training that Stanislavsky's system is well represented, one of his trainings is "Circles of Attention". He develops in future actors targeted observation of others, their characteristics and habits. All this forms a holistic idea of the variety of characters, their types, varieties of temperament. Thus, we can conclude that the great director foresaw the future in the educational process of theatrical higher educational institutions, offering training as a special form of activity.

In the process of training sessions, students not only learn new skills in the profession, but also gain experience for real life, form new ideas about life and about the profession.

Questions of creative activity are always acute, important and topical: after all, as a result of it, something original should be born, to a certain extent unique, and in general qualitatively new. Only creative activity generates that which promotes progress, makes life qualitatively different, more interesting. The recognition of this fact forces scientists to direct their research in search of new, previously unknown ways and methods of solving problems posed by life. In this regard, all the problems accompanying the creative process, the atmosphere of creativity have been and will always be relevant and important for ensuring positive changes in the life of human society. At the moment, the importance of studying the phenomenon of creativity has a steady tendency to increase. What is today the driving factor that contributes to the increase in the importance of research on creative activity in modern conditions?

There are a number of factors that we consider to be the most important in solving this problem. Among them:

1) dialectics of the dynamism of the development of modern society;

2) globalization and integration of society itself;

3) awareness by society of the need for dynamic improvement of all spheres of life in accordance with its realities;

4) the creation of qualitatively new values for society and humanity, which determine positive conditions for its further, successful development.

Thus, we can conclude that creative activity is a whole world, a special culture, which teachers of creative universities are called to develop, on the basis of already accumulated experience with the introduction of elements of a new one, dictated by life itself and the realities of the confidently marching XXI century, and all the achievements of the world science must be put into the service of Uzbek pedagogy, which has been developing so dynamically in recent years, to fulfill the tasks set by our government in the field of higher education.

\section{References}

[1] Electronic

source: https://www.lex.uz/docs/5013009 Law of the Republic of Uzbekistan "On Education" No. 3PУ-637 dated 23.09.2020

[2] Bespalko V.P. Pedagogy and progressive teaching technologies. M., 2005, 87 p. 
[3] Voinova M.G. Possibilities of using pedagogical innovations in teaching theoretical and practical disciplines. // Coll. Theoretical and practical aspects of teaching languages and literature in universities (issue VI) T., 200435 p.

[4] Alekseev N.A. Personally-oriented learning: questions of theory and practice Tyumen: Publishing house of TSU, 1996, $216 \mathrm{p}$.

[5] Azizkhodzhaeva N.N. Pedagogical technologies in teacher training. T., 2000, $58 \mathrm{p}$.

[6] Karimov, I.A. Report of the President at the meeting of the Cabinet of Ministers of the Republic of Uzbekistan, dedicated to the results of socio-economic development of January 18, 2013

[7] A.A. Leontiev. Psychological units and the generation of speech utterance. - M., Science D 969, p. 91.

[8] K. Stanislavsky: The Art of Presentation. Classical sketches of acting training St. Petersburg, ed. group "Azbuka - classic", 2010 